\title{
31. RESULTS OF DOWNHOLE GEOPHYSICAL LOGGING HOLE 396B, DSDP LEG 46
}

\author{
R. James Kirkpatrick ${ }^{1}$, Scripps Institution of Oceanography, University of California at San Diego, La Jolla, California
}

\section{INTRODUCTION}

The downhole logging of Hole 396B on Deep Sea Drilling Project Leg 46 was the first attempt to obtain in situ physical property data in Layer 2 of the oceanic crust, and one of the few published logging attempts in basaltic rocks (Zablocki et al., 1974; Keller et al_, 1974; Siems et al., 1973, 1974; Crosby and Anderson, 1971). Hole 396B is about $160 \mathrm{~km}$ east of the Mid-Atlantic Ridge at $22^{\circ} 59.14^{\prime} \mathrm{N}, 43^{\circ} 30.90^{\prime} \mathrm{W}$. The oldest sediments cored from above the basalt are middle Miocene, about 13 million years old (Leg 46 Shipboard Party, this volume). The depth of the hole is 405.5 meters. The hole was logged from the base of the casing at 163 meters to about 370 meters, depending on the tool. The top of the basement is at 150.5 meters (Leg 46 Shipboard Party, this volume).

The original objectives of the logging program were to determine, in situ, physical properties and the positions of the lithologic contacts in the hole, especially in intervals of poor recovery. Within the limitations of the tools used, these objectives were met.

Because logging instruments are not standard oceanographic tools, this paper will first present a summary of the tools used and their limitations. It will then present the data and address the following questions:

1) What are the tools measuring?

2) How precise are the measurements?

3) How representative of the in situ values are the data?

4) How well can the logs be used to distinguish different rock types?

5) How well can the logs be used to determine lithologic boundaries?

6) What do the logging data tell us about the state of the upper part of Layer 2 at this site?

\section{LOGGING PROCEDURE AND TOOLS}

The logging tools were provided by Schlumberger, Ltd., and include compensated sonic velocity, compensated density,(gamma-gamma) compensated neutron porosity, electrical resistivity (Dual Induction - Laterolog 8), and natural gamma ray. No caliper data were obtained. Temperature data are reported by Erickson and Hyndman (this volume). Because of the drill string's minimum $3 \%$ inch $(9.84 \mathrm{~cm})$ inside diameter, none of the positioning devices (centralizers or decentralizers) on any of the tools could be

\footnotetext{
${ }^{1}$ Present address: Department of Geology, University of Illinois, Urbana, Illinois.
}

used. This lack of positioning devices is an important restriction on quantitative use of the data, because the positions of the tools (mostly about $3 \% / 8$ in. [8.6 cm] O.D.) in the hole (nominally 10 in. $[25.4 \mathrm{~cm}]$ ) are not well known. The tools are mostly of the compensated type (more than one receiver), however, and the effects of mispositioning do not seem to be great if average data are used. Because of this problem, only average data for intervals 4 meters or longer will be used.

The following discussion of the tools comes primarily from the Schlumberger Log Interpretation manual (Schlumberger, 1972a, b).

The sonic velocity tool (compressional velocity only) consists of two sets of one transmitter and two receivers each. The interval transit time is obtained by alternately pulsing each transmitter and averaging the travel time difference between the two receivers for each set. This compensation procedure, similar to reversing a seismic refraction line, eliminates most of the sonde-tilt and hole-size effects. The data are recorded continuously as travel time $(\mu \mathrm{s} / \mathrm{ft})$, and no corrections to the data on the log are necessary. Because no positioning devices were used on any of the tools, these data are probably the most accurate of all the logging data ( $R$. Aguilar, personal communication). The tool investigates only a few centimeters into the rock.

The density tool used is also compensated. It consists of a directional gamma ray source and two directional gamma ray detectors at different distances from the source. The difference in count rate between the two detectors is converted to electron density in the rock, which is converted to mass density. For most rock types, including basalts, no corrections to the log data are necessary. The tool investigates to a depth of about $15 \mathrm{~cm}$. The mud-cake correction, which has already been made, is plotted on the log along with the density.

The neutron tool used is compensated in a way similar to the density log. It consists of an $\mathrm{Am}-\mathrm{Be}$ neutron source and two neutron detectors at different distances from the source. Comparison of the response of the two detectors eliminates much of the sonde-tilt and hole-size effects. The neutrons respond primarily to hydrogen atoms, although boron and chlorine have some effect. Since most but not all of the hydrogen in the rock is in pore water, it is necessary to make some corrections which are not considered automatically in the data reduction process. For Hole 396B some of these effects are significant. Because the temperature in the hole was low, but the pressure high (about half a kilobar), there is a pressure correction of minus 10 per cent of the log value (C. Clavier, personal communication). In addition, there is 
a minus 4 porosity per cent hole-size correction (10 in. hole versus an 8 in. standard condition) and a minus 2 porosity per cent bound-water correction. If the tool was not at the side of the hole, there is also a minus 3 porosity per cent per inch standoff correction. If the tool was in the center of the hole there is thus a minus 11 porosity per cent correction. In Hole 396B the tool was most probably lying on the side of the hole, even without the decentralizers, because the hole was almost certainly not vertical (R. Aguilar, personal communication). Therefore, no standoff correction has been made. The depth of investigation of the neutron tool depends on water content, but is less than about a foot.

The resistivity tool used (Dual Induction-Laterolog 8) consists of two induction tools which investigate to about 60 inches (ILD) and 40 inches (ILM), and a focused electrode tool (LL8) which investigates closer to the hole. The two induction tools measure conductivity (which is converted to resistivity) in a horizontal plane perpendicular to the hole. The electrode tool measures components of both the horizontal and vertical resistivity. Because the current is carried primarily by the pore fluid, it is necessary to know the resistivity of the pore fluid to make quantitative interpretations of the resistivity data. The downhole temperature measurements of Erickson and Hyndman (Leg 46 Shipboard Party, this volume) indicate that this fluid is seawater at about $2.5^{\circ} \mathrm{C}$. This will be assumed in this paper.

The natural gamma ray tool used measures the total gamma ray activity reaching the sonde. In most rocks this activity may be ascribed to ${ }^{40} \mathrm{~K}$ and the elements of the uranium and thorium decay series. Quantitative interpretation of the data is difficult, and will not be attempted here. Intervals of high natural gamma ray activity do, however, correspond to intervals of low sonic velocity and density and high porosity. The higher activities almost certainly arise from the potassium content of palagonite breccia, which is higher than in unaltered basalt.

\section{DATA}

The five logs obtained are presented, along with a generalized lithologic column, in Figure 1. Four major lithologic units were identified in the basement (Leg 46 Shipboard Party, this volume). The interval from 150.5 meters to 235.5 meters (Units 1 and 2) is a sequence of sparsely phyric basalt containing olivine and plagioclase phenocrysts, with some palagonite breccia and lithified nannofossil ooze in the upper part. The section between 235.5 meters and 243 meters (Unit 3) is a sparsely phyric basalt flow. From 243.0 to 310 meters (Unit 4) is an olivine and plagioclase phyric basalt pillow sequence. The interval from 310.0 to 405.5 meters (Units 5 through 8 ) is a sequence of basaltic pillows, breccia, sand, and gravel; recovery in this interval was very poor.

The average values for the downhole data to be used quantitatively, and coring and recovery data and a lithologic column, are presented in Figure 2. Where the values are marked O.S., the data are off scale on the processed logs, for which no backup scale was provided. The values, if presented, are taken from the on-site optical logs. Both interval travel time $(\mu \mathrm{s} / \mathrm{ft})$ and sonic velocity $(\mathrm{km} / \mathrm{s})$ are presented for the sonic log. For the neutron log both the uncorrected and corrected values are given. Data for all three resistivity instruments are presented, although the ILD and LL8 fall so close to each other that they are plotted together.

The resistivity data require some special explanation. The observation is that the deep-investigating ILD and the shallow-investigating LL8 always track close to each other, and the intermediate-investigating ILM tracks with the other two in low-resistivity intervals and below in high-resistivity intervals (good basalt). This is because of the large borehole correction that must be applied to the ILM log at high resistivities (C. Clavier, personal communication). The correction is necessary because a significant amount of the induced current sensed is in the borehole. The corrections to the ILD and LL8 logs are small, about 10 per cent. Given the lack of positioning devices, this correction is probably less than the accuracy of the data, and will not be made.

\section{DISCUSSION}

Before the logging data can be used to make geological or geophysical interpretations, it is important to understand where the physical properties are being measured, what the precision of the data is, and how representative the data are of the in situ conditions.

It is clear from Figures 1 and 2 that the measurements are of rocks and that none of the values are for water, even though the hole may be washed out, as is likely in the sand. From the available descriptions of the tools, it seems that except for the induction tools the measurements are coming from within about a foot of the borehole.

Plots of the different data against each other can be used to test the precision of the data. For the Leg 46 data they seem to indicate that the precision is comparable to that of the shipboard laboratory data.

Probably the best test is the porosity-density plot shown in Figure 3. The position of a data point on this plot is related to grain density, which should be about 2.8 to $2.9 \mathrm{~g} / \mathrm{cm}^{3}$ for these rocks (Leg 46 Scientific Party, this volume; Hyndman and Drury, 1976; Christensen and Salisbury, 1975). The values for most intervals in Hole 396B fall within this range. In addition, in the high density range the log and laboratory data overlap. The point labeled sand is from the lowest density part of the inferred sand and gravel interval, and probably reflects inaccurate measurements caused by collapse of the hole. The hole terminated because the drill bit stuck in this material. The palagonite breccia, labeled " $P$," should have lower grain densities. That this does not appear to be true for the logs, as the one shipboard palagonite measurement indicates, may be a result of an insufficient bound-water correction for the palagonite.

It appears that for most of the data points the precision of measurement, even without the positioning devices, is a few porosity per cent and 0.1 or $0.2 \mathrm{~g} / \mathrm{cm}^{3}$ for density. if the two tools are inaccurate, they are inaccurate in proportion to each other and in the same direction.

Velocity and density (Figure 4) also show a consistent relationship. Most of the logging data fall along the linear fit for oceanic basalts of Christensen and Salisbury (1975). This line is also close to a linear extrapolation of the shipboard data for Hole 396B (Leg 46 Shipboard Party, this volume). Again, in the high density range the laboratory and log data 


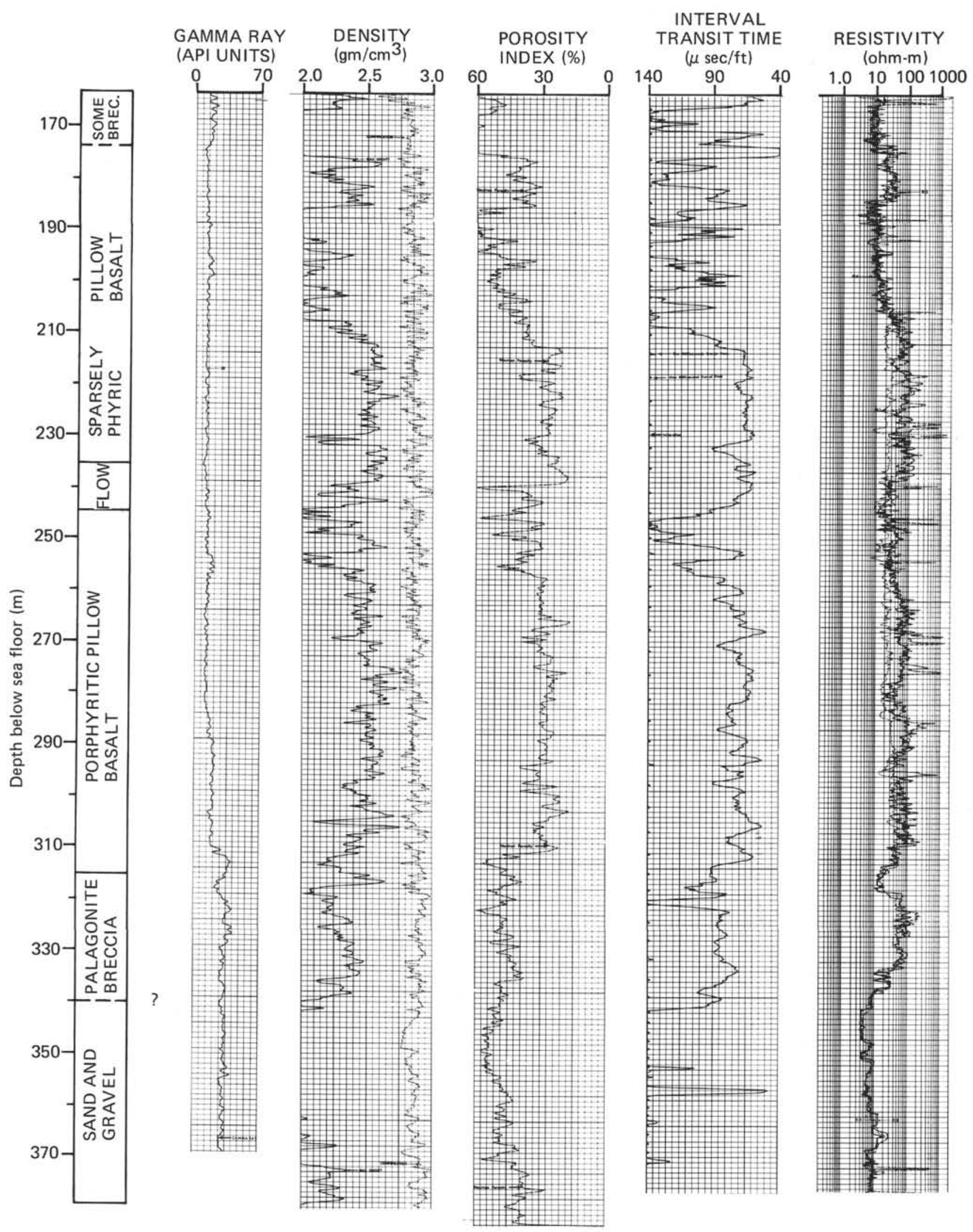

Figure 1. Processed logs for Hole 396B, with generalized lithologic column. 


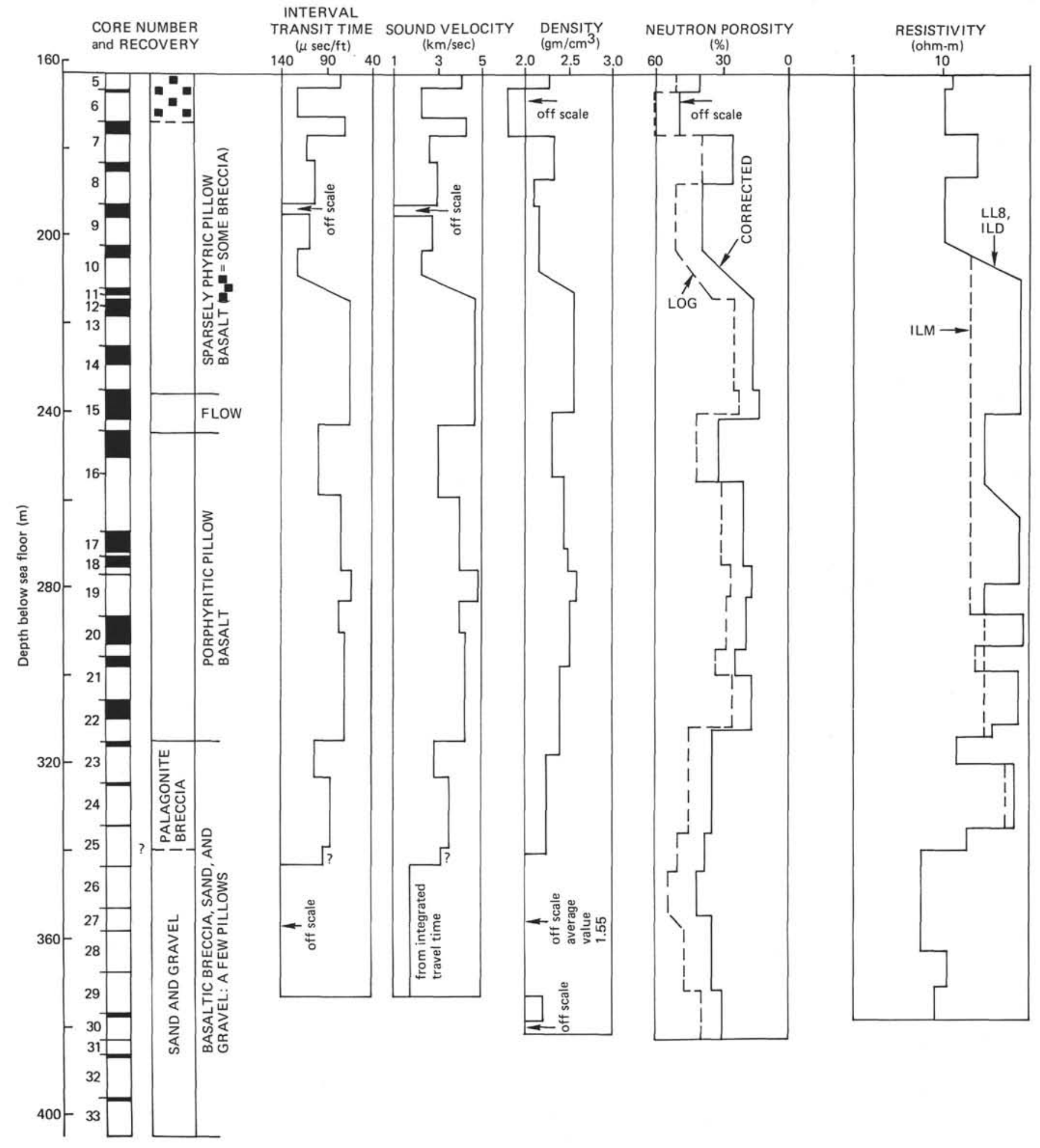

Figure 2. Interval averaged values for the Hole 396B log data, with lithologic column and recovery (dark) for each core. O.S. indicates that the values were off scale on the processed logs, for which no backup scale was provided. Values come from on-site optical logs.

overlap. At low densities the data fall well below the nonlinear fit of Christensen and Salisbury (1975). This may reflect the unconsolidated nature of the low-density material.

The velocity and porosity data (Figure 5 ) from the logs also fall along a linear extrapolation of the shipboard data. Again, where the shipboard and log data are in the same porosity range, they are in agreement. The Wyllie relationship

$$
\phi=\frac{\Delta \mathrm{t}_{\log }-\Delta \mathrm{t}_{\mathrm{g}}}{\Delta \mathrm{t}_{\mathrm{f}}-\Delta \mathrm{t}_{\mathrm{g}}},
$$

where $\phi$ is porosity, $\Delta \mathrm{t}_{\mathrm{log}}$ is the log travel time, $\Delta \mathrm{t}_{\mathrm{g}}$ is the grain 


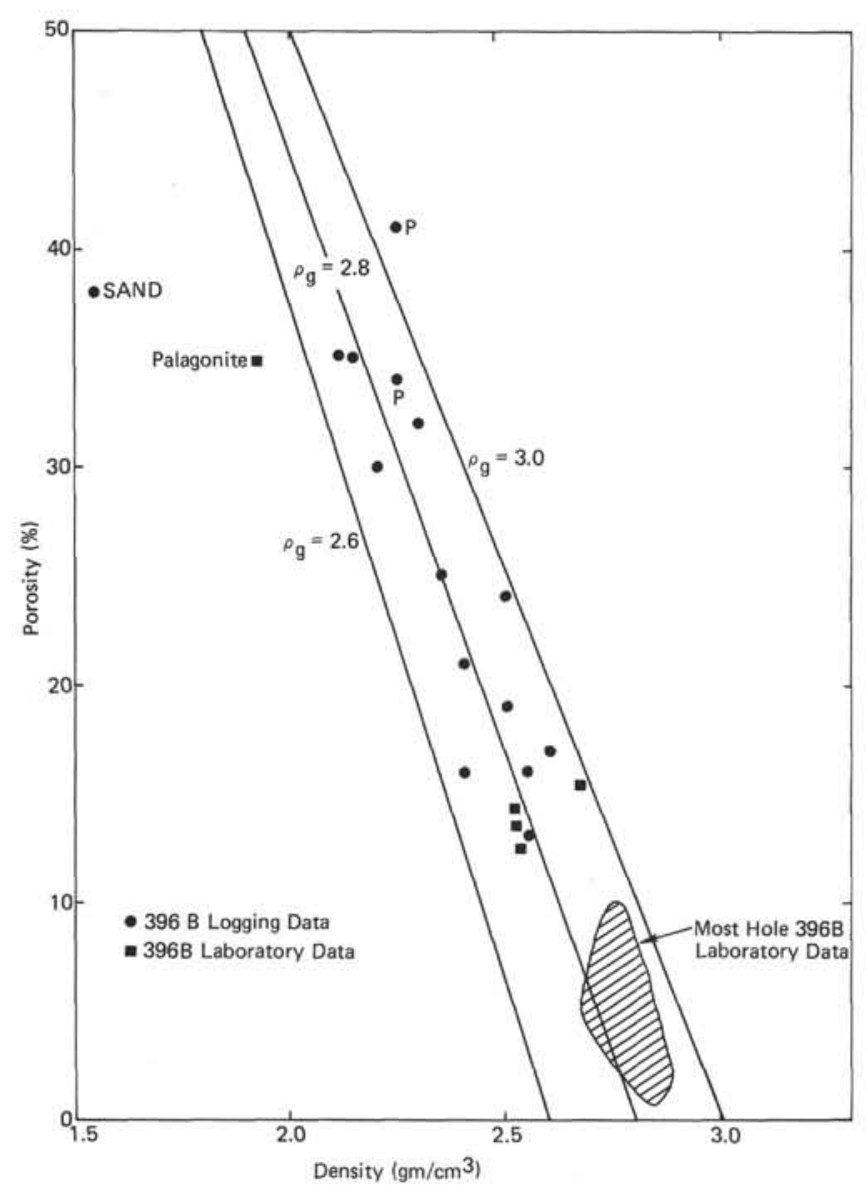

Figure 3. Corrected neutron porosity versus density for the Hole 396 B logs.

travel time, and $\Delta \mathrm{tr}$ is the fluid travel time (Wylie et al., 1956,1958 ), falls below the observed values, except for the palagonite breccia, at porosities above about 35 per cent. One of the palagonite breccias plots above the general trend, possibly because of an insufficient bound-water correction to the porosity. The sand falls well below the general trend, perhaps because it is much less consolidated or because of poor data quality in this possibly collapsed part of the hole.

Figure 6 is a plot of formation resistivity factor versus porosity for the laboratory data (Christensen and Hyndman, this volume) and logging data for Hole 396B. The formation resistivity factor $(\mathrm{F})$, the ratio of rock resistivity to pore water resisitivity, must be used in any comparison of data, because the water restivity can vary. Christensen and Hyndman obtained their data at room temperature with seawater $\left(R_{w}=\right.$ $0.2 \mathrm{ohm}-\mathrm{m}$ ) in the pores. The pore fluid in the hole is also most likely sea water, but at about $2.5^{\circ} \mathrm{C}$ (Erickson and Hyndman, this volume). A fluid resistivity of $0.4 \mathrm{ohm}$-meter has been assumed.

As with the other data, the logging data fall on a linear extension of the laboratory data, and the two types of data nearly overlap.

Formation factor has been found (Archie, 1942) to be related to porosity, $\phi$, by the relationship

$$
\mathrm{F}=\mathrm{C} \phi^{-m}
$$

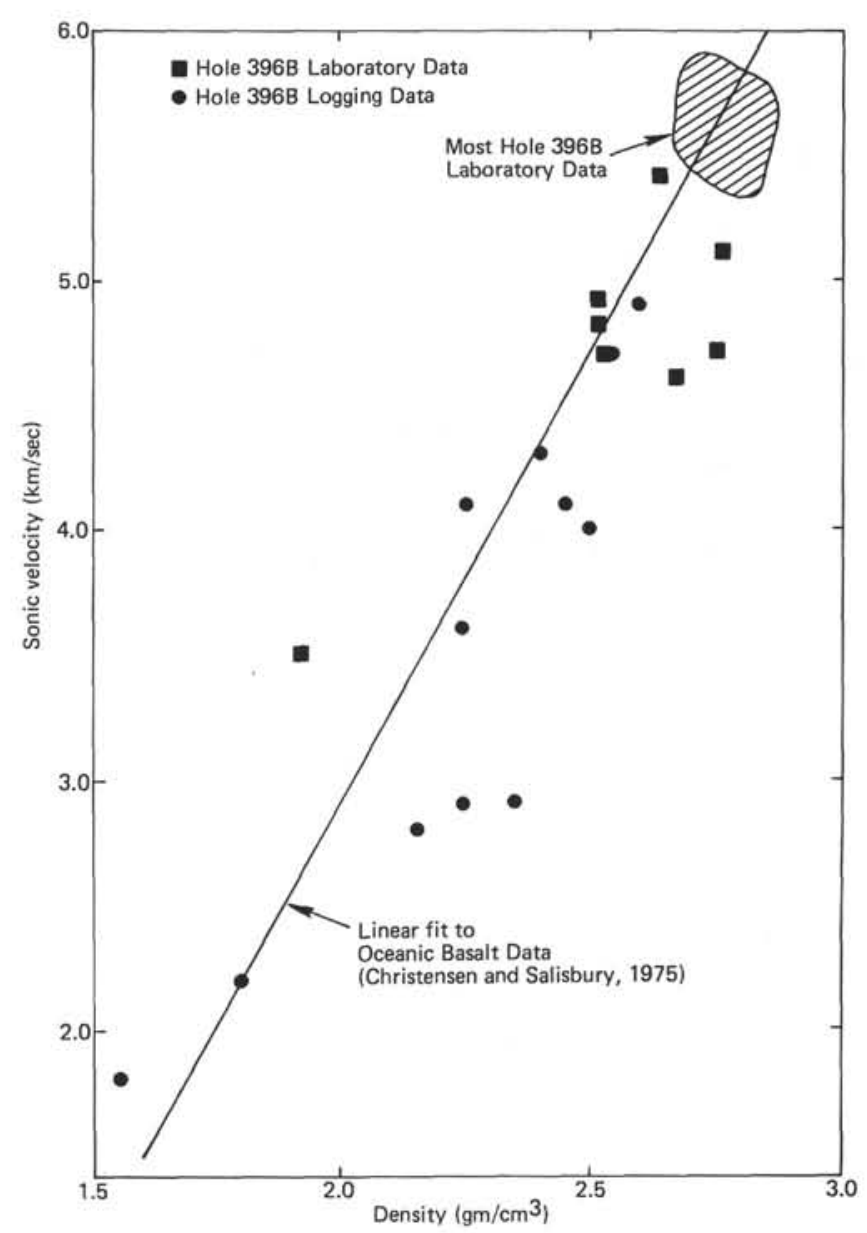

Figure 4. Sonic velocity versus density for the Hole $396 B$ logs and shipboard sample data, along with the linear fit for oceanic basalts of Christensen and Salisbury (1975).

where $\mathrm{C}$ is a constant and $m$ is related to the way the pores are distributed (Hyndman and Drury, 1976). If the pores are randomly distributed, as in a normally cemented sandstone, $m$ is about 2. For uncemented materials $m$ is less than 2, and for materials with less than randomly connected pores $m$ is greater than 2 .

A linear least-squares fit of the log and laboratory data gives an exponent of 1.33. For the log data alone, the slope is 1.80 and for the laboratory data alone, 1.2. This is in good agreement with $\log$ and laboratory data for Hawaiian basalts, which have an exponent of about 0.9 to 1.0 (G. Keller, personal communication). It does not, however, agree with the exponent of about 2.5 found by Hyndman and Drury (1976) for laboratory samples of DSDP Leg 37 basalts. The origin of this difference is not clear, but may be related to the clay-mineral distribution (M. Drury, personal communication).

For the log data, at least, this low exponent seems to imply that the pores are connected better than in a consolidated sandstone, and that given the high porosities, the permeability is probably high.

A most significant and intractable question is whether the downhole data are representative of the in situ values away from the hole. As noted above, the rock near the hole could 


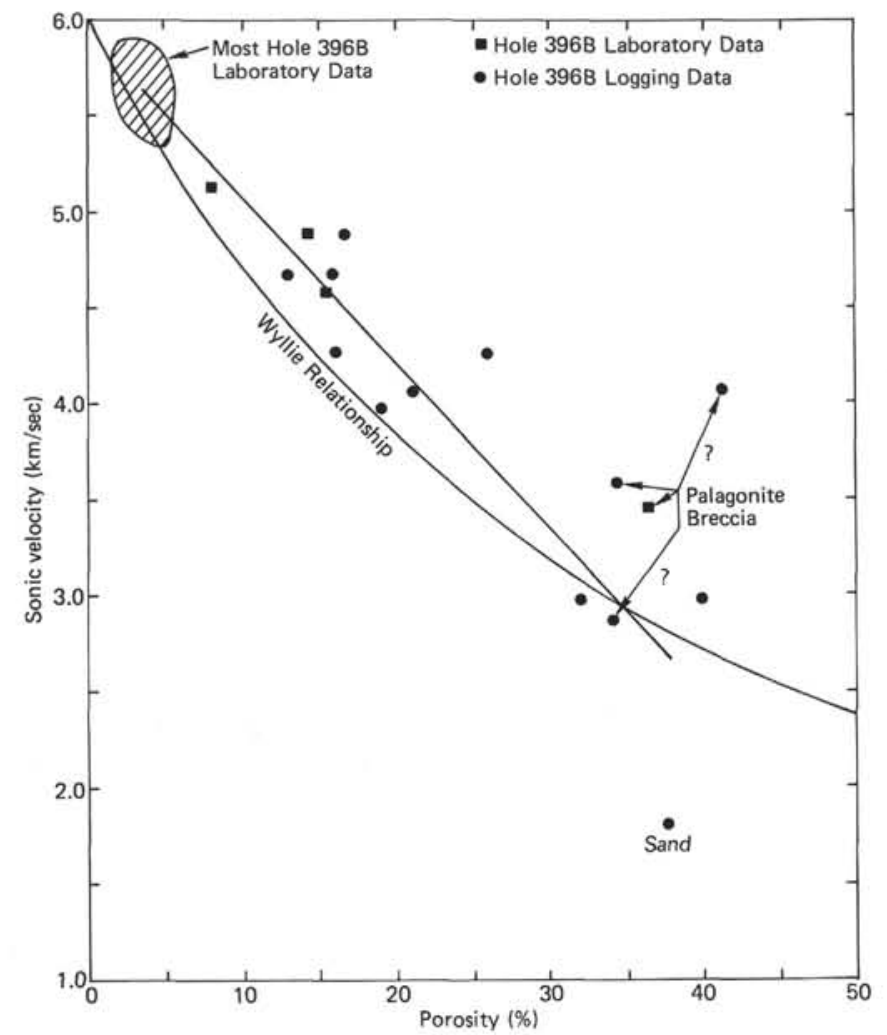

Figure 5. Sonic velocity versus porosity for Hole $396 \mathrm{~B}$ log and shipboard sample data.

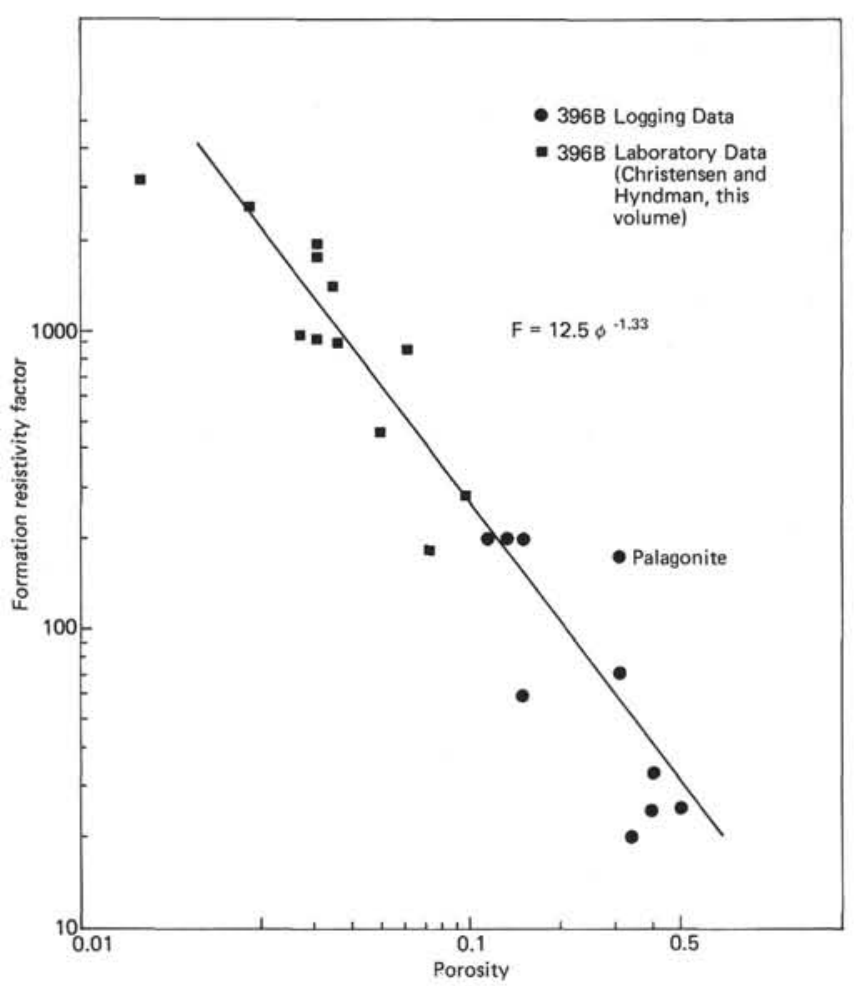

Figure 6. Formation factor versus porosity (rock resistivity/ pore fluid resistivity / for Hole $396 \mathrm{~B} \log$ data, assuming a pore fluid resistivity of $0.4 \mathrm{ohm}$-meters, along with laboratory measurements of Hole $396 \mathrm{~B}$ samples, assuming a fluid resistivity of 0.2 ohm-meters /Christensen and others, this volume). be fractured and the hole wall could be extremely irregular, giving rise to logging data which may not be correct for the crust as a whole. Two different lines of evidence indicate that the $\log$ data probably represent the true values.

Comparison of the integrated sonic velocity from the log with velocities for the upper part of Layer 2 determined by marine refraction methods indicates that the downhole data lie within the observed range. The integrated velocity for the interval logged, 163 to 370 meters, is $3.1 \mathrm{~km} / \mathrm{s}$. If the sand and gravel unit is excluded, and of all the DSDP holes which have penetrated 200 meters or more into Layer 2 , this is the only time such a thick unit has been found, the average velocity is $3.6 \mathrm{~km} / \mathrm{s}$. Both these values are much less than the average velocity of about $5.5 \mathrm{~km} / \mathrm{s}$ determined for ocean floor basalts by Christensen and Salisbury (1975) and for the returned material at Site 396 (Leg 46 Shipboard Party, this volume). These are, however, within the range of 3.0 to 4.5 $\mathrm{km} / \mathrm{s}$ for upper Layer 2 velocities in 13 million-year-old crust (Houtz and Ewing, 1976). The average laboratory value for basalt does not fall within their range until the crust is about 20 million years old. At the very least, then, the log velocities are a lower boundary for the true velocity at this location, and are probably closer to the true velocity than those indicated by the laboratory measurements.

Corroborating evidence comes from the variation of resistivity with distance from the hole. If there was extensive damage to the rock near the hole, we should expect the LL8 resistivity to be lower than the ILD resistivity. In fact, they are always very close to each other. This implies that, to the extent that formation damage would decrease the resistivity, there is little damage or the damage is constant out to at least 60 inches from the hole (unlikely).

These two pieces of evidence, taken together, indicate that, on the average, hole damage is not extensive and the log data are probably not far from the true in situ values.

\section{USE OF THE LOGGING DATA}

One of the important uses of the downhole data is in identifying rock types and lithologic boundaries in intervals where recovery is poor. A major objective of this first experiment with logging in the oceanic crust was to determine how well logging can perform this task.

Comparison of the logs and the recovered core shows clearly that boundaries between grossly different rock types can be distinguished well and that in many cases the rock types can be distinguished uniquely. All the important boundaries can be picked on all the logs except the resistivity $\log$, and rock types can be distinguished using a combination of tools. It should be noted that only lithologic changes which significantly affect the physical properties can be detected. Changes in basalt chemistry or texture apparently cannot be detected with the present set of tools.

Three major rock types were encountered in Hole 396B: basalt, palagonite (hydrated basaltic glass) breccia, and basaltic sand and gravel (perhaps slightly cemented) (Leg 46 Shipboard Party, this volume). All of these can be distinguished one from another using the logging data. The basalt ( 210 to 240 and 256 to $315 \mathrm{~m}$ ) can be distinguished by its relatively high sonic velocity ( 4.0 to $4.8 \mathrm{~km} / \mathrm{s})$, density ( 2.4 to $2.6 \mathrm{~g} / \mathrm{cm}^{3}$ ), and resistivity (up to $95 \mathrm{ohm}-\mathrm{m}$ ), and relatively low porosity (13 to $21 \%$ ). For the most part, the good basalt falls along uniform trends on the 
porosity-density, porosity-velocity, density-velocity, and formation factor-porosity plots.

The palagonite breccia ( 310 to $340 \mathrm{~m}$ and perhaps 163 to $167 \mathrm{~m}$ ) can be distinguished by its high velocity-porosity ratio (Figure 5) and its high $m$ value on the formation factor-porosity plot (Figure 6). Both of these characteristics may be ascribable to an insufficient bound-water correction to the neutron porosity data, resulting in an overestimate of the porosity. In principle, the grain density for the palagonite should be less than for basalt. That this is not the case in Figure 3 may again be the result of an overestimate of the porosity.

The sand and gravel unit (below $340 \mathrm{~m}$ ) can easily be distinguished by its low velocity $(1.8 \mathrm{~km} / \mathrm{s})$, low density $\left(1.55 \mathrm{~g} / \mathrm{cm}^{3}\right)$, and low resistivity (less than $\left.10 \mathrm{ohm}-\mathrm{m}\right)$.

There are, however, intervals where correlation between the logs and the core is not clear. This is especially true in the upper parts of the sparsely phyric and porphyritic pillow basalt units. In the sparsely phyric basalt unit we recovered a little palagonite breccia with pillow basalt to a depth of about 174 meters. The high natural gamma ray activity also ends here. The highly irregular character of the logs in this interval, however, extends to a depth of about 210 meters. This discrepancy probably results not from lack of recovery of breccia between 174 and 210 meters, but from open fractures or cavities (pillow centers?) which extend to 210 meters. In the upper part of the porphyritic basalt unit, the velocity, density, and resistivity are low and the porosity high, but only pillow basalt was recovered. Once again, palagonite breccia was not recovered and the natural gamma response is still low. It seems likely that there are open fractures or cavities here also. If there are, then pillow sequences may be identifiable by a change from high velocity, density, and resistivity and low porosity at the bottom to lower velocity, density, and resistivity and higher porosity at the top, but with the data plotting on the general basalt trend on the porosity-density, porosity-velocity, density-velocity, and formation factor-porosity diagrams.

All the lithologic boundaries in Hole 396B can be identified using any of the logs except resistivity, which identifies some. The aphyric pillow-basalt/basalt-flow contact, however, cannot be identified at all, except perhaps by a slight porosity decrease in the flow. The flow/porphyritic-basalt contact is identifiable in all logs, and the porphyritic-basalt/palagonite-breccia contact is identifiable except with resistivity. Position of the breccia/sand-and-gravel contact is defined by the logs. It seems likely that similar contacts could be determined in other holes if logging were available.

\section{CONCLUSIONS - THE STATE OF THE CRUST}

If we can rely on the inferences drawn from the lack of radial variation in resistivity and from comparison of the integrated sonic velocity from the logs with the geophysically determined velocities for the upper part of Layer 2, the data presented in Figure 2 may be a good first approximation of the true physical state of the interval logged at Site 396.

Perhaps the most impressive result is the overall high porosity and low density throughout the hole. Even in the massive basalt flow the porosity appears to be about 13 per cent - much higher than the average laboratory value of about 4 per cent. This seems to imply that the porosity is on a scale larger than the core samples, i.e., large open fractures and cavities. This is in agreement with the inferred conditions at Mid-Atlantic Ridge Sites 332 and 333 (Hyndman and Drury, 1976). It is also in good agreement with the apparently good connection between the pores, indicated by the porosity-formation factor plot. Such large openings, combined with the overall high porosity, would seem to imply high permeability through the sequence drilled.

One important conclusion from this first logging experiment is that more logging in the oceanic crust is needed. Logging is the only way presently available to determine a suite of in situ physical properties, and is the only way to determine lithologic boundaries in intervals of poor recovery. There is also a need for additional tools to help resolve some of the ambiguities in the present data. Interval velocity would go a long way toward finally determining the extent of disturbance around the bore hole, and a continuous temperature $\log$, and perhaps downhole fluid sampling, would insure proper interpretation of the resistivity data.

\section{ACKNOWLEDGMENTS}

I wish to thank R.E. Boyce, J. Severns, J. Heirtzler, R. Hyndman, C. Clavier, M. Drury, and G. Keller for their many useful discussions and comments during the course of this work, and Rudy Aguilar for collecting the original data. R.E. Boyce and J. Severns reviewed the manuscript.

\section{REFERENCES}

Archie, G.E., 1942. The electrical resistivity $\log$ as an aid in determining some reservoir characteristics, Pet. Tech., v. 5.

Christensen, N.I. and Salisbury, M.H., 1975. Structure and constitution of the lower oceanic crust, Rev. Geophys. Space Phys., v. 13, p. 57-86.

Crosby, J.W. and Anderson, J.V., 1971. Some applications of geophysical well logging to 'basalt hydrogeology, Ground Water, v. 9, p. 13-20.

Houtz, R. and Ewing, J., 1976. Upper crustal structure as a function of plate age, J. Geophys. Res., v. 81, p. 2490-2498.

Hyndman, R.D. and Drury, M., 1976. The physical properties of oceanic basement rocks from deep-drilling on the Mid-Atlantic Ridge, J. Geophys. Res., v. 81, p. 4042-4052.

Keller, G.V., Murray, J.C., Skokan, J.J., and Skokan, C.J., 1974. CSM research drill hole at summit of Kilauea Volcano, The Mines Mag., May, p. 14-18.

Schlumberger, Ltd., 1972a. Log Interpreation, Volume I. Principals, p. 113.

, 1972b. Log Interpretation, Volume 2 - Charts, p. 92.

Siems, B.A., Crosby, J.W., Anderson, J.V., Bush, J.H., and Webere, T.L., 1973. Final report, geophysical investigation of Washington's ground water resources, Wash. State Univ. Col. of Engineering Res. Div. Rept. No. 73/15-81.

Siems, B.A., Bush, J.H., and Crosby, J.W., 1974. $\mathrm{TiO}_{2}$ and geophysical logging criteria for Yakama basalt correlation, Columbia Plateau, Geol. Soc. Am. Bull., v. 85, p. 1061-1068.

Wyllie, M.R.J., Gregory, A.R., and Gardner, G.H.F., 1956. Elastic wave velocities in heterogeneous and porous media, Geophysics, v. 21, p. 41.

, 1958. An experimental investigation of factors affecting elastic wave velocities in porous media, Geophysics, v. 23 , p. $459-493$.

Zablocki, C.J., Tilling, R.I., Peterson, D.W., Christianson, R.I., Keller, G.V., and Murray, J.C., 1974. A deep research drill hole at the summit of an active volcano, Kilauea, Hawaii, Geophys. Res. Letters, v. 1, p. 323-326. 